\title{
Promoting Students' Generic Skills with the Integration of e-Service Learning Platform
}

\author{
https://doi.org/10.3991/ijet.v14i20.11455 \\ Valerie Bukas Marcus ${ }^{(凶)}$, Noor Azean Atan, Rohaya Talib, Adibah Abdul Latif, \\ Sanitah Mohd Yusof \\ Universiti Teknologi Malaysia, Johor Bahru, Malaysia \\ valeriebukas92@gmail.com
}

\begin{abstract}
Related previous studies have recognized service learning ability to improve students' generic skills during the service learning projects, however strategies for implementing and evaluating the effects of service learning on students' generic skills in online environment remain limited. Therefore, this study conducted to identify what are the generic skills mentioned in students' reflections, the differences when the responses compare to students' performance in the course, and to analyze students' perception towards the integration of e-Service Learning platform. A learning environment was created using faceto-face with integration of online delivery of service learning. By the end of the course, thirty-five students were required to reflect upon their learning process while using the e-Service Learning platform. Results showed that the design of the learning environment was effective in promoting the development of these generic skills such as Global Citizen, Scholarship, Adaptability and Teamworking. The major contribution of this study is that generic skills can be promoted through the hybrid strategy of service learning that combine both face-toface and online delivery. Academic success is strengthened both via the use of technologies as well as through the implementation of experiential learning opportunities such as service learning.
\end{abstract}

Keywords-E-Service Learning; Generic Skills; Online Learning; Learning Environment

\section{Introduction}

Service Learning was known to have a lot of benefit in term of academic performance, social and emotional development among students that participated in it. Service Learning is a proven pedagogy for fostering transformational learning in every discipline. Service Learning is an evolution from the core assumptions of the educational philosopher and theorist John Dewey $(1916,1939)$ who encouraged learning by doing. Service Learning has been defined in numerous ways in recent years. While there is no "one-size-fits-all definition, The National and Community Service Act of 1990 define Service Learning as an educational experience that connects educational institutes to community where students can actively participate in community service 
and apply their academic theories and concept into real life application that meet community specific needs.

Service Learning has a positive effect on understanding of social issues, personal insight and cognitive development [1] Students participating in Service Learning program demonstrated significant gains in five outcome areas: civic engagement, social skills and academic performance [2].In term of generic skills, analysis of students' reflection in [3] shows that most student find the service learning experience has improved their communication skills, trained them to apply their organizational skills and task distribution skills. From individual aspect, participating student are not only able to gain a deeper understanding of their existing knowledge but also acquire new knowledge which can be academic in nature and specific skills such as communication skills in the context of multicultural society, collaborative working skills and perception in gender difference. Apart from that, a study shows that Service Learning can be the enabler to develop a quality leadership practices in [4]

However, all these studies were carried out in conventional teaching method which is through face-to-face. As instructors transitioning to online learning platforms due to its potential for providing more flexible access to content and instruction at any time, from any place, Service Learning have the risk of being left behind. Many instructors abandon their Service Learning efforts when migrating to teaching in online platform because they view the online medium as a barrier to Service Learning. In reality, online platform can be a facilitator rather than barrier to Service Learning. e-Service Learning is not merely a pedagogical curiosity, but it holds the key to the future of Service Learning [5]. This is because e-Service Learning is able to transform both Service Learning and online learning by freeing Service Learning geographical constraints and equipping online learning with a tool to promote engagement as online learning always perceived to have lack of engagement and interaction among the students. Although this e-Service Learning strategy was introduced for quite sometimes, but there still seems lacking research that investigate the effect of this strategy in depth particularly how e-Service Learning is able to promote generic skills among the students.

With this in mind, there are three objectives to accomplish in this study. Firstly, is to identify what are the generic skills mentioned in students' reflection and secondly to identify what are the difference between students' response compared to students' performance in the course that integrate with e-Service Learning platform. Lastly, we would like to analyze students' perception towards the integration of e-Service Learning platform. Major contribution of this study would be gratifying for educators who plan to incorporate e-Service Learning into their courses in addition to produce a future proof graduates with competence generic skills we aspired to produce. 


\section{$2 \quad$ Literature Review}

\subsection{Generic skills}

Generic skills (also refer to key skills, graduates' attributes, core skills, life skills, competencies, work related skills, employment skills, transferable skills, personal skills and others) are widely explore and gaining interest among researchers over a decade in society, education and even in the workplace.

Universities are increasingly marketing their "successful" students to industry using graduates' attributes as a measure of that success [6]. Generic skills also have been used to measure the success of a course [7]. In university, generic skills have been taught separately for example, course on speech communication, presentation skills or have been embedded within subjects (e.g. a critical thinking course as a part of research class).

There is also research evidence indicating that generic skills develop when students were involved in collaborative learning [8]. Recent study in [9] explored the factors explaining the learning of generic skills from the perspective of university students' experience. Their finding suggests that teaching practices involving collaboration and interaction as well as features of a constructivist learning environment and integrative instructional style predicted the learning of generic skills such as decision-making skills, different forms of creativity and problem-solving skills. Meanwhile, conventional method of university teaching such as reading, lecturing and working individually were negatively related with the learning of generic skills. This supported in [10] stating that active learning experiences nurture intellectual capabilities meanwhile collaboration activity which required communication and teamworking skills were developed through group activity.

However, there seems to be a gap of studies regarding the learning of generic skills in online environment. In the recent study explore business students' soft skills in online learning environment in [11], researchers reported that self-motivation, social skills and self-regulated learning are the major factor of success to enhance soft skills in online course. Based on literature above, we see the need to explore more what is the role of online platform in promoting students' generic skills.

In this study, there are mainly four generic skills that researcher wanted to investigate which is implemented in the course learning outcomes. There are Adaptability, Scholarship, Teamworking and Global Citizen. Adaptability is described as the ability to adapt to the culture of new communities and work environment, ability to apply known solutions to new situations and ability to work under pressure. Meanwhile, Scholarship is a skill to seek and manage relevant information from a variety of sources, be receptive to new ideas towards self-directed or autonomous learning and the ability to use systematic research methodology. Teamworking is the ability to establish rapport, interact and work effectively with others to accomplish common objectives, ability to lead and influence team members to complete given tasks and understand responsibility towards group decision. Lastly, Global Citizen skill is the ability to understand the impact of socio-cultural, economic, environmental and poli- 
tics on professional practices and act ethically in making decisions and interacting with the community.

\section{$2.2 \quad$ E-Service learning}

E-Service Learning occurs when the instructional component, the service component, or both are conducted online [5]. It is important to highlight that the term eService Learning somehow overlaps with the concept service-eLearning which introduced in [12]. They described service-eLearning as "an integrative pedagogy that engage learners through technology in civic inquiry, service, reflection and action" (p.1). According to [5] there are four types of e-Service Learning. There are Hybrid Type I where service fully conducted on site with teaching fully online, service fully online with teaching fully online as Hybrid Type II, a blended format of instruction and service done partially online and also on site known as Hybrid Type III and lastly, the extreme e-Service Learning which instruction and service was done fully online. Different types of e-Service Learning may produce different products and outcomes. They are also having different service and course learning outcomes. As for this study, researcher define the e-Service Learning as Hybrid Type III due to the nature of the course that researcher want to investigate. Future research recommends from [5] is that to advance e-Service Learning pedagogy by having better understanding of eService Learning outcomes which call for this purpose of study. In addition to this, many researches were carried out solely on the effectiveness of authentic learning principles in service learning however there is lack of research that relate these two components in online platform.

The success and challenges of facilitating service learning in online platform is discussed in [13]. They reported that the service learning was successful in term of its ability to fulfil the institution goal, reaching and impacting national and global communities, easing long-term commitment in communities and witnessing the evolution of individual change are among the most valuable. Students were required to travel outside of local regions to provide needed assistance throughout the United States and beyond as the web-based service learning courses extend wider access to learning within a context of geographic, socio-cultural and economic diversity. Students that participate in this experience and engaging with peers were exposed to a rich environment that promotes deep learning.

Case study methodology has been utilized in [14] by interviewing 12 participants who successfully completed student-led e-Service Learning (SLESL) projects. Their analysis of transcribed interview revealed a number of interesting findings regarding the effectiveness of student-lead e-Service Learning projects. Their findings were divided into five categories:

- Reasons for engaging

- Project strategies

- Project assets and assets mobilization

- Course interaction

- Project outcomes 
The project outcomes category focused on the tangible and intangible outputs resulting directly from the project activities and consisted of five pillars: awareness and community engagement, clientele needs served, structures, tangible resources, and other community needs. This shows that learners nowadays is not only focusing on the interaction and knowledge with the world around them, but they seek an education experience that will help them to develop generics skills to apply in real life situation particularly for their career in the future.

Based on these previous literatures, it is important to highlight that Service Learning can be done through online platform and produce the same outcomes as the traditional method of service learning. However, due to the lack of engagement in fully online Service Learning project, researcher called to use the Hybrid Type III of eService Learning proposed in this study. The only drawback of this Hybrid Type III of e-Service Learning is that students involved were required to travel for service. However, this is not a big issue as nowadays we can easily access e-hailing transport provider. In addition, some students have their own transport, and this make the process of conducting the Service Learning project is so much easier.

Apart from that, e-Service Learning is also able to fill in the gap of learning style for millennials. By merging Service Learning and e-Learning, millennials will always have unlimited access to vast amount of information at the same time pairing best practices of educational technology to address their community needs.

\section{$3 \quad$ Methodology}

\subsection{Participants}

The setting for this study is in one of the local universities in Malaysia. It involved 35 undergraduates' students who participated in one of the Service Learning courses. All these students came from across discipline that participated together to conduct a service learning project for the community regarding Information and Communication Technology (ICT) involved three primary schools as their community subject.

\subsection{Instruments}

This study is using an online platform, questionnaire, reflection questions and evaluation rubrics as research instruments. An online platform has been set up for this purpose of research. A set of questionnaires regarding students' perceptions towards service learning program is used. It consists of 5 questions to identify the impact on an online platform in a contribution of the Service Learning program. Respondents were required to answer the statements provided according to their level of agreement starting Strongly Agree until Strongly Disagree.

Apart from that, the researcher is using evaluation rubrics provided to assess student generic skills such as scholarship, global citizen, teamworking and adaptability. This rubric was provided by the instructor of the course for fair evaluation. According to this rubric, there are 4 main learning tasks that students need to complete. There are 
Finding Information, Outdoor Class Project, Service Learning Activity and Final Report of Service Learning or Reflections from the students. The weightage of each generic skills is shown in Table 1.

Table 1. Marks distribution for Generic Skills

\begin{tabular}{|l|c|l|}
\hline Generic Skills & Marks & \multicolumn{1}{|c|}{ Description } \\
\hline Scholarship & 20 & $\begin{array}{l}\text { A skill to seek and manage relevant information from a variety of sources, be } \\
\text { receptive to new ideas towards self-directed or autonomous learning and the ability } \\
\text { to use systematic research methodology. }\end{array}$ \\
\hline Teamworking & 30 & $\begin{array}{l}\text { Ability to establish rapport, interact and work effectively with others to accomplish } \\
\text { common objectives, ability to lead and influence team members to complete given } \\
\text { tasks and understand responsibility towards group decision, }\end{array}$ \\
\hline Global Citizen & 20 & $\begin{array}{l}\text { Ability to understand the impact of socio-cultural, economic, environmental and } \\
\text { politics on professional practices and act ethically in making decisions and inter- } \\
\text { acting with the community. }\end{array}$ \\
\hline Adaptability & 30 & $\begin{array}{l}\text { Ability to adapt to the culture of new communities and work environment, ability } \\
\text { to apply known solutions to new situations and ability to work under pressure }\end{array}$ \\
\hline TOTAL & \multicolumn{2}{|c}{100} \\
\hline
\end{tabular}

Meanwhile, reflection questions were provided by the end of the course that consists of three questions as below:

- Describe your service learning in detail and explain why your service is needed?

- How do you feel about the experience?

- What were your expectations?

In the reflection, students were required to describe their service learning in detail in as a recap activity. They were also needed to explain why their service required as a critical examination on the purpose of their Service Learning project. Upon reflecting question (2), students will share about their learning experience throughout the project. Researcher anticipated to analyze their generic skills in this question. Finally, third question is about students' expectation before and after the Service Learning project. This question enables students to reflect that their initial expectation could be wrong or even gave them a better insight and perspective about Service Learning. This process will help students to change their perceptions about Service Learning.

\subsection{Procedure and data collection}

Researcher has planned and carried out action research in one of the Service Learning courses which involve a group of 35 students who are taking the course in the second semester of $2018 / 2019$. Students were given about fifteen weeks to complete the course. The assessment for the course was carried out in two phases. The first phase involves preparing a proposal for the project. Once their proposal was accepted, they need to implement it in a real-life situation which is the Service Learning program as their platform. Data collected for the evaluation rubric is from the proposal submitted by the students and their overall project implementation documentation and also final report. These marks from learning activities will be used to assess whether 
generic skills stated in the course outline is achieved. At the end of the course, students were required to write their reflection upon their learning process in the course. Written reflection allows students sufficient time to process their thought and provide meaningful insight. Students' reflections are analyzed using content analysis that has been quantified based on the evaluation rubrics produced specifically focusing on Scholarship, Adaptability, Teamworking and Global Citizen. Researcher then focused to determine if any differences could be found between "higher performers" and "lower performers." Final course grade was used to differentiate these groups of students. For the purposes of this study, "higher performers" are operationally defined as students assigned a grade of "A," and "A+". "Lower performers" are operationally defined here as students assigned a grade of "A-" or lower. Though researcher do not wish to suggest that a "A-" student constitutes a low performer, in the context of this course, and given how the grades usually are assigned, a grade of "A-" reflects average marks for this course. Questionnaires were distributed as student completed their project. The data collected from the questionnaire were analyzed using descriptive statistics to identify student's perceptions about the integration of e-Service Learning platform.

\section{Results and Discussion}

\subsection{Students' reflection on service learning experience}

The first objective of this study is to determine what are the generic skills mentioned in students' reflection based on the learning outcomes provided by course instructor. Table 2 show the percentage of generic skills mentioned in students' reflection.

Table 2. Generic Skills in Students' Reflection

\begin{tabular}{|l|c|c|c|c|}
\hline & Adaptability & Global Citizen & Scholarship & Teamworking \\
\hline Overall & 30 & 32 & 31 & 21 \\
\hline Percentage (\%) & 85.71 & 91.43 & 88.57 & 60.00 \\
\hline
\end{tabular}

Based on the table above, $91.43 \%$ of students mentioned about their role as Global Citizen in their reflections as they are going through the service learning project. Student reflected this generic skill as in following comments below:

S2: "My service work is critically needed especially for these young children to develop and equip themselves with ICT knowledge for their own future."

One international student reflects upon this skill as stated below:

S3: "The whole experience had a huge impact on me personally, it made me feel even better about how good I am since I was able to reach those kids and communicate with them and make them like me even though we spoke in English which is not their mother tongue, because as far as my knowledge goes, children will always give their honest opinions about anyone." 
Also significant to student is their skill to adapt during the service learning course. One of the students commented "I have made friends with students from other faculty, enhance my communication skills and gain new experiences with the children throughout this project". Meanwhile, another student claimed:

S4: "This event gave me more chance to get closer with my classmates. Make new friends. Make some great memories and gave me very exciting story to share with my friends back at home."

Another remarkable comment by one of international student regarding how service learning promotes his adaptability is "At the beginning I was afraid with service learning will not good enough because I am a foreigner and I do not know how to socialize with local student. But I got very helpful team, they motivated me to go beyond my limit."

Apart from this, student realized their scholarship skill also important while conducting the service learning project. One student said, "We also learn about making budgets and necessary paperwork's for any project and about submitting proposal to the authority about our plan and budget." Similarly, one student noted, "Most importantly, we as students learnt on how to conduct a program. We could also enhance our editing skills as we also need to learn the editing tools before we teach those students."

Interestingly, overall only $60 \%$ of the student mentioned about their teamwork skills in their reflection. One of the students said, "I was able to get to know new friends from various faculties and cooperate with them under one organization." The director the project noted "Aside from that, I anticipated the development of different skills such as teamwork and leadership. It turned out well, as I was elected as the director of this program and I had to coordinate everybody so the event would turn out really fine." Similarly, the vice director of the program said, "Throughout the service learning, I learnt the way to cooperate with others since all the activities requires team working."

Researcher believed that global citizen became the most skill reflected in students' reflection was due to the nature of this service learning course. As the course involved students from across discipline in university, internationally and locally, students were required to mingle, and this process actually promotes their global citizen skill. On top of that, students need to interact and communicate with a real community, in this case they need to go to a primary school and have a chance to engage with primary school students and teachers involved. In addition, as student explored the community needs, they recognized that there are some critical community needs. For example, one student in her reflection stated that she realized some of the primary school student do not know the basic knowledge and skills on how to operate the mouse and keyboard, so she was called to teach them the basic skill first then only proceed to their main agenda. As Global Citizen attribute was mentioned highly in students' reflection, this proves that they are able to understand the impact of their service to socio-cultural, economic, environmental and politics. These findings were supported by other studies indicating that majority of the students that involved in service learning project will developed in their civic responsibility and awareness in [2, 3, 14-16]. 
Meanwhile, adaptability and scholarship skill reflected averagely high in students' reflection. As the Service Learning course required students to work with different people from various background, this trigger their inner survival skills which is the ability to adapt to the culture of new communities and work environment. Students also reflect upon their ability to work effectively under pressure as the Service Learning course need to be completed in less than 15 weeks, not to mention various last minutes task that they need to handle due to unavoidable circumstances. This finding was supported by previous study in [14] as the participants in the study stated that despite many challenges they face during the project, they were able to complete it. Some participant even interacted with the instructor to process their challenges. Likewise, in this study, many students always refer back to their instructor and appreciate their instructor willingness to guide and help them in order to accomplish the service learning project. The role of instructor during the course is notably important in order to support adaptability skill among the students.

Apart from that, the Service Learning course is able to promote their Scholarship skill as we can see some students reflect upon their ability to seek and manage relevant information from a variety of sources. They also realize they need use systematic research methodology in order to complete the proposal and wrapping up the Service Learning course as they reflected in their reflection. Other studies have supported these findings indicating that service-learning project helped students learn the course material, feel more connected to the surrounding community, and improve their communication and problem-solving skills for their careers [17].

Interestingly, team working skills was not reflected as much as researcher expected. This might be because of there are only some of the student that taking a leadership role meanwhile the others are merely just a follower. Therefore, the percentage of students reflected upon their team working skills is quite low compare to other skills. This finding is contradicted with other studies that reported service learning increase leadership and team working skills among students [3, 4].

\subsection{Students' performance during service learning course compared to their reflections}

The second objective of this study is to determine if any difference existed between high performing and lower performing students in the service learning course. Table 3 show the generic skills reflected in students' reflection among high performing students.

Table 3. Generic Skills reflected among High Performing Students

\begin{tabular}{|l|c|c|c|c|}
\hline & Adaptability & Global Citizen & Scholarship & Team working \\
\hline High Performers (Out of 23) & 20 & 22 & 22 & 16 \\
\hline Percentage (\%) & 86.96 & 95.65 & 95.65 & 69.57 \\
\hline
\end{tabular}

Based on the table above, Global Citizen is still the highest skill reflected the most even among the high performing students together with Scholarship skill with the percentage of $95.65 \%$. It is then followed by Adaptability with $86.96 \%$ and the lowest 
skill reflected is Team working with $69.57 \%$. Meanwhile, Table 4 show the generic skills reflected in students' reflection among high performing students.

Table 4. Generic Skills reflected among Low Performing Students

\begin{tabular}{|l|c|c|c|c|}
\hline & Adaptability & Global Citizen & Scholarship & Team working \\
\hline Low Performers (Out of 12) & 10 & 10 & 9 & 5 \\
\hline Percentage (\%) & 83.33 & 83.33 & 75.00 & 41.67 \\
\hline
\end{tabular}

Interestingly among the low performing students, Adaptability and Global Citizen are the most skill mentioned in students' reflection with $83.33 \%$ though not as high percentage as in high performing students. Next skill is their scholarship with $75 \%$ and the least skill reflected in their reflection is Teamworking with only $41.67 \%$.

From these findings, the two groups of were similar in term of Global Citizen is still the highest skill mentioned in students' reflection and Teamworking is still the lowest reflected skill. The only difference is that, high performance students reflected about their Scholarship skill as the highest attribute in their reflection compared to Adaptability among low performance students apart from Global Citizen. The only reason that researcher could think of is perhaps student in the high performance group valued the process of seeking and managing relevant information throughout the Service Learning course. As they are exploring something new while preparing for the project, students discovered new knowledge that they never learnt before in their own discipline. This could possibly contribute the reason behind highest percentage of Scholarship skill in their reflection. Meanwhile, student in the low performance group might value their skill in adaptability as they need to work together with many students that came from various discipline that is different with them. Consequently, they appreciate the connection formed throughout the participation. This is actually contrast with study in [18] as she found out that higher performance student was the one that valued connection with others compared to lower performance student.

\subsection{Students' Perception toward the integration of e-Service Learning platform}

Last objective of this study is to identify students' perception towards the integration of e-Service Learning platform. Researcher believe that the online learning platform prepared for the purpose of the Service Learning course have a great impact to students as it provides them a flexible platform to plan and prepare for their service learning project. Table 5 shows the analysis of students' perception toward the integration of e-Service Learning platform.

Table 5. Students' Perception towards the Integration of e-Service Learning platform

\begin{tabular}{|l|c|c|c|c|c|c|}
\hline \multicolumn{1}{|c|}{ Items } & $\begin{array}{c}\text { Strongly } \\
\text { Disagree }\end{array}$ & Disagree & Average & Agree & $\begin{array}{c}\text { Strongly } \\
\text { Agree }\end{array}$ & Mean \\
\hline $\begin{array}{l}\text { The online platform provided } \\
\text { sufficient learning resources for my } \\
\text { service learning activities }\end{array}$ & 0 & 0 & 4 & 16 & 15 & 4.31 \\
\hline
\end{tabular}




\begin{tabular}{|l|l|l|l|l|l|l|}
\hline $\begin{array}{l}\text { The online platform encouraged me } \\
\text { to interact with the designer of the } \\
\text { site and with my friends through } \\
\text { different communication tools } \\
\text { (email, chat, forums) }\end{array}$ & 0 & 0 & 1 & 18 & 16 & 4.43 \\
\hline $\begin{array}{l}\text { The online platform helped me to } \\
\text { track my learning progress } \\
\text { throughout the service learning } \\
\text { activities }\end{array}$ & 0 & 0 & 2 & 14 & 19 & 4.49 \\
\hline $\begin{array}{l}\text { The online platform included } \\
\text { rubrics to evaluate my performance } \\
\text { based on assessment given }\end{array}$ & 0 & 0 & 4 & 16 & 15 & 4.31 \\
\hline $\begin{array}{l}\text { The online platform is well pre- } \\
\text { pared with real life task to solve } \\
\text { throughout the service learning } \\
\text { activities }\end{array}$ & 0 & 0 & 4 & 14 & 17 & 4.37 \\
\hline MEAN & & & & & & \\
\hline
\end{tabular}

Referring to Table 5, most of the respondents acknowledge that the online platform consists of interactive features provided sufficient learning resources for their service learning activities. They also agreed that the online platform encourage them to interact with lecturers and friends through different communication tools such as chat and forums provided. Apart from that, large number of respondents admit that the online platform helped them to track their learning progress throughout the service learning activities. They also complied that the online platform included rubrics to evaluate their performance based on assessment given. Lastly, they further agree that the online platform is well prepared with real life task to solve throughout the service learning activities. Hence, mean value for this questionnaire is 4.38 which show that student agree that online platform did contribute in part of their Service Learning program.

Large number of respondents acknowledge that online platform does have impact in the contribution of Service Learning program in term of helping them tracking their learning progress throughout the service learning activities. Research suggests that service learning can gain greater relevance when integrated with e-Learning pedagogy as the future will be faced by millennial learners and this will bring benefits to them in order to communicate globally and operate in advance technological systems [12]. Researcher believe that this function in the online platform help students involved in viewing their overall performance. This component is crucial as the Service Learning course always have ongoing task that they need to complete continuously as they are giving their service to the community. Likewise, [19] supported this finding by saying that it is more manageable to utilize this pedagogy over an online platform as the ongoing engagement, examination, analyses and review of students' participants is required to ensure the success of the course. Furthermore, students were also benefitted from this highly interactive online platform. 


\section{Conclusion}

In this study, researcher is able to identify what are the generic skills reflected in students' reflection. Skill that most student reflected is Global Citizen. From this service learning course, student realized their ability to understand the impact of socio-cultural, economic, environmental and politics on professional practices. Apart from that, they also reflected upon their ability to be receptive to new ideas towards self-directed or autonomous learning as in their Scholarship skill. Similarly, they notably realized their Adaptability skill while doing the service learning project as they need to adapt to the culture of new communities and work environment. Though there is a slight difference between percentage of skills reflected among high and low performing student, reasons for the differences observed are not clear from these data. However, it is assuring to know that regardless of how well they perform in the class, all students got something and that something they report receiving is consistent with the skills that we aspired to produce among our university graduates. In fact, students were also able to acquire and improve their soft-skills or more known as graduates' attributes through this technology-integrated, project-based service learning. These include teamwork and problem-solving skills as well as effective oral and communications skills which are highly desirable for employment in these days. Apart from that, students perceived the integration of e-Service Learning platform as something positive especially how the online platform is able to help them track their learning progress.

With the integration of e-Service Learning in delivering the content, students able to experience globalized online learning. Design of the learning environment was effective in promoting the development of these generic skills, and that the authentic activities were instrumental in motivating students. Once motivated, students then actively engaged with self-directed and reflective activities which helped construct knowledge and promote generic skill development. By using reflection through this combination of service learning pedagogy and online course format, students are empowered to both assess their individual learning goals as well as collaborate with other to make meaning of their individual service learning experience. Future study is recommended to critically reflecting on the role of technology in facilitating academic and civic learning outcomes in depth. The major contribution of this study is that generic skill development and deep approaches to learning can be achieved without having to take extra time to specifically teach these skills. Developing generic skills becomes a natural consequence of students actively engaging with learning tasks that are authentic, student-centered and reflective be it in online or face-to-face delivery method.

\section{References}

[1] P. L. Yorio and F. Ye, "A meta-analysis on the effects of service-learning on the social, personal, and cognitive outcomes of learning," Academy of Management Learning \& Education, vol. 11, no. 1, pp. 9-27, 2012. https://doi.org/10.5465/amle.2010.0072 
[2] C. I. Celio, J. Durlak, and A. Dymnicki, "A Meta-analysis of the Impact of ServiceLearning on Students," Journal of Experiential Education, Article vol. 34, no. 2, pp. 164181, 2011. https://doi.org/10.5193/jee34.2.164

[3] K. Osman, "The Inculcation of Generic Skills through Service Learning Experience among Science Student Teachers," Procedia - Social and Behavioral Sciences, vol. 18, pp. 148153, 2011/01/01/ 2011. https://doi.org/10.1016/j.sbspro.2011.05.022

[4] B. Romsa, K. Romsa, J. Lim, and S. Wurdinger, "Undergraduate Sport Management Students' Perceptions of Leadership Skills Through Service Learning," Journal of Leadership Education, vol. 16, no. 2, 2017. https://doi.org/10.12806/v16/i2/r8

[5] L. S. Waldner, M. C. Widener, and S. Y. McGorry, "E-service learning: The evolution of service-learning to engage a growing online student population," Journal of Higher Education Outreach and Engagement, vol. 16, no. 2, pp. 123-150, 2012.

[6] J. Daniels and J. Brooker, "Student identity development in higher education: Implications for graduate attributes and work-readiness," Educational research, vol. 56, no. 1, pp. 65-76, 2014. https://doi.org/10.1080/00131881.2013.874157

[7] K. Yajima, K. Kawasaki, Y. Kubota, and A. Takahshi, "Objective Assessment of Students' Generic Skills," in 2018 IEEE International Conference on Teaching, Assessment, and Learning for Engineering (TALE), 2018, pp. 567-572: IEEE. https://doi.org/10.1109/tale. $\underline{2018.8615136}$

[8] M. Laal and S. M. Ghodsi, "Benefits of collaborative learning," Procedia - Social and Behavioral Sciences, vol. 31, pp. 486-490, 2012/01/01/ 2012. https://doi.org/10.1016/j.sbspro. $\underline{2011.12 .091}$

[9] A. Virtanen and P. Tynjälä, "Factors explaining the learning of generic skills: a study of university students' experiences," Teaching in Higher Education, pp. 1-15, 2018. https://doi.org/10.1080/13562517.2018.1515195

[10] D. Kember, "Nurturing generic capabilities through a teaching and learning environment which provides practise in their use," Higher Education, journal article vol. 57, no. 1, pp. 37-55, January 01 2009. https://doi.org/10.1007/s10734-008-9131-7

[11] H. Tseng, X. Yi, and H.-T. Yeh, "Learning-related soft skills among online business students in higher education: Grade level and managerial role differences in self-regulation, motivation, and social skill," Computers in Human Behavior, vol. 95, pp. 179-186, 2019. https://doi.org/10.1016/j.chb.2018.11.035

[12] A. Dailey-Hebert and E. Donnelli, "Service-eLearning: educating today's learners for an unscripted future," International Journal of Organizational Analysis, vol. 18, no. 2, pp. 216-227, 2010/05/25 2010. https://doi.org/10.1108/19348831011046272

[13] K. L. Guthrie and H. McCracken, "Making a difference online: Facilitating servicelearning through distance education," The Internet and Higher Education, vol. 13, no. 3, pp. 153-157, 2010. https://doi.org/10.1016/j.iheduc.2010.02.006

[14] B. J. Goertzen and J. Greenleaf, "A student-led approach to eService-learning: A case study on service project effectiveness within a fieldwork in leadership studies course," The International Journal of Research on Service-Learning and Community Engagement, vol. 4, no. 1, 2016.

[15] J. M. Conway, E. L. Amel, and D. P. Gerwien, "Teaching and learning in the social context: A meta-analysis of service learning's effects on academic, personal, social, and citizenship outcomes," Teaching of Psychology, vol. 36, no. 4, pp. 233-245, 2009. https://doi.org/10.1080/00986280903172969

[16] B. Hasbún, C. Miño, C. Cárdenas, O. Cisternas, C. Fara, and F. Garcia, "Service-Learning as a Means to Promote Development of Social Responsibility Competency in a Depart- 
ment of Economics and Business (English translation)," The International Journal of Research on Service-Learning and Community Engagement, vol. 4, no. 1, 2016.

[17] S. J. Lee, C. Wilder, and C. Yu, "Exploring students' perceptions of service-learning experiences in an undergraduate web design course," Teaching in Higher Education, vol. 23, no. 2, pp. 212-226, 2018/02/17 2018. https://doi.org/10.1080/13562517.2017.1379486

[18] R. A. Litke, "Do All Students' Get It?': Comparing Students' Reflections to Course Performance," Michigan Journal of Community Service Learning, vol. 8, no. 2, 2002.

[19] K. L. Guthrie and H. McCracken, "Reflection: the importance of making meaning in eservice-learning courses," Journal of Computing in Higher Education, vol. 26, no. 3, pp. 238-252, 2014. https://doi.org/10.1007/s12528-014-9087-9

\section{$7 \quad$ Authors}

Valerie Bukas Marcus, Noor Azean Atan, Rohaya Talib, Adibah Abdul Latif and Sanitah Mohd Yusof all work for Universiti Teknologi Malaysia, at Skudai, Johor Bahru, in Malaysia.

Article submitted 2019-07-06. Resubmitted 2019-08-14. Final acceptance 2019-08-14. Final version published as submitted by the authors. 